\title{
Building capacity in tobacco control by establishing the Eastern Europe Nurses' Center of Excellence for Tobacco Control
}

\author{
Stella A. Bialous', Iveta Nohavova ${ }^{2,3}$, Eva Kralikova ${ }^{2,3,4}$, Marjorie J. Wells' , Jenny Brook ${ }^{5}$, Linda Sarna ${ }^{6}$
}

\begin{abstract}
INTRODUCTION Properly educated nurses delivering evidence-based tobacco dependence treatment could contribute to improving health and reducing regional disparities in tobacco-related disease and death in Central and Eastern Europe. The aims of this study are to describe development of the Eastern European Nurses' Centre of Excellence for Tobacco Control (COE) and evaluate its online educational program on tobacco dependence treatment using the 5As framework. METHODS The online education evaluation followed a prospective, single group, pre- and post-assessment of changes in nurses' self-reported tobacco cessation interventions. Leaders from five Eastern European countries (Hungary, Czech Republic, Romania, Slovakia, Slovenia) developed protocols for in-country tobacco control education. Nurses responded to a baseline survey, accessed an online nursing educational program, and completed a follow-up survey at 3 months, in the period December 2015 to June 2016. A total of 695 nurses from five countries answered questions on cessation interventions at baseline and of these 507 (73\%) completed a follow-up survey at 3 months.

RESULTS At the follow-up at 3 months, the 507 nurses self-reported a significant increase in providing all $5 \mathrm{~A}$ components, i.e. nurses were significantly $(\mathrm{p}<0.0001)$ more likely to always / usually advise a patient to quit, assess interest in quitting $(\mathrm{p}=0.002)$, assist with a quit plan, review barriers to quitting and recommend a smoke-free home post-discharge (all $p<0.0001$ ). They were also significantly more likely $(p=0.01)$ to agree or strongly agree that nurses have an obligation to advise patients on the risks of smoking. There was a significant increase $(\mathrm{p}<0.0001)$ in nurses' estimate of the number of patients they provided a cessation intervention the previous week. Nurses who smoked were $60 \%$ more likely to assist and arrange compared to nurses who never smoked.

conclusions Coordinating multi-country activities through a COE was successful in engaging a network of nurses to use an online educational program and participate in other tobacco control activities.
\end{abstract}

\author{
AFFILIATION \\ 1 School of Nursing, University \\ of California San Francisco, San \\ Francisco, United States \\ 2 Institute of Hygiene and \\ Epidemiology, 1st Faculty of \\ Medicine, Charles University, \\ General University Hospital, Prague, \\ Czech Republic \\ 3 Society for Treatment of Tobacco \\ Dependence, Prague, Czech \\ Republic \\ 4 Centre for Tobacco-Dependent, \\ 3rd Department of Medicine, \\ 1st Faculty of Medicine, Charles \\ University, General University \\ Hospital, Prague, Czech Republic \\ 5 School of Medicine, University \\ of California, Los Angeles, United \\ States \\ 6 School of Nursing, University of \\ California Los Angeles, Los Angeles, \\ United States
}

CORRESPONDENCE TO

Stella A. Bialous. School of Nursing, University of California San Francisco, 3333 California Street, San Francisco, CA 94118, United States. E-mail: stella.bialous@ ucsf.edu

\section{KEYWORDS}

practice, e-learning, health knowledge, nursing education, tobacco cessation interventions, Central and Eastern European nurses

Received: 29 June 2020

Revised: 31 August 2020

Accepted: 7 October 2020

\section{INTRODUCTION}

Goal 3 of The United Nations 2030 Sustainable Development Goals (SDG) focuses on good health and well-being, including efforts to reduce tobacco use. The engagement of the world's 20 million nurses and midwives will be pivotal to meeting the $\mathrm{SDG}^{1-3}$, 
especially the target of reducing global tobacco use by $30 \%$ by $2030^{4}$. Smoking remains a major contributor of all-cause mortality in Europe $e^{5,6}$, with a marked disparity in rates of tobacco use between Western and Central and Eastern Europe ${ }^{7,8}$. The involvement of properly educated nurses in the delivery of evidencebased tobacco dependence treatment could contribute to reducing these regional disparities ${ }^{9}$. However, there is a paucity of published research evaluating evidence-based strategies to educate nurses in tobacco dependence treatment, especially for nurses working in non-English speaking countries.

The WHO Framework Convention on Tobacco Control (FCTC) ${ }^{10}$ Article $14^{11}$ highlights the need to educate all healthcare professionals to integrate cessation as part of standard care and encourage health professionals to offer a cessation intervention to all tobacco users in all encounters ${ }^{12}$. Nurses are uniquely positioned to implement Article 14 and offer cessation assistance to patients as they are in contact with patients, families and communities in a variety of healthcare settings ${ }^{13-15}$.

\section{Educating nurses in Central and Eastern Europe about tobacco control}

Education of nurses about tobacco control needs to consider both appropriate content and delivery methods and the $5 \mathrm{As}$ is an evidence-based approach that can be adapted across health settings ${ }^{12}$. Earlier efforts focused on educating nurses in the Czech Republic through a training of trainers (ToT) model. The content included tobacco use prevalence and health impact, principles of addiction, behavioural therapy, and evidence-based recommendations for cessation including the 5As approach and pharmacotherapy. It also included examples on how to approach patients. Three months after participation, nurses who attended the educational program were significantly more likely to provide patients who smoke with evidence-based cessation interventions compared to baseline $\mathrm{e}^{1,12,14-16}$.

While the ToT model was successful, the number of nurses reached was limited. Therefore, the content was adapted into an online educational program with web-based country-specific resources for the Czech Republic and Poland, developed following a model successfully implemented in several states in the United States and two cities in China ${ }^{13,14,16-22}$. At
3 months follow-up, nurses were significantly more likely to provide smoking cessation interventions to patients who smoke and refer patients for cessation services than at baseline ${ }^{13}$. The purpose of this study is to describe the development and outcome of an online educational program provided to nurses in Central and Eastern Europe through the Eastern Europe Nurses' Centre of Excellence for Tobacco Control. This work describes the first three years (2014-2017) of the Centre. The Republic of Moldova was added as a sixth country in 2017.

\section{METHODS}

\section{Developing a Nurses' Centre of Excellence in Tobacco Control}

To scale up efforts to build nursing capacity for addressing tobacco dependence in Central and Eastern Europe, the Eastern Europe Nurses' Centre of Excellence for Tobacco Control (hereafter referred to as $\mathrm{CoE}$ ) was established in Prague, Czech Republic, in January $2014^{23}$. The CoE is a partnership effort of the International Society of Nurses in Cancer Care (ISNCC) in collaboration with the Centre for TobaccoDependent of the 3rd Department of Medicine at the General University Hospital, Prague, with expert support from the Schools of Nursing, University of California, Los Angeles, and University of California, San Francisco. The CoE is hosted by the Society for Treatment of Tobacco Dependence, Prague.

The CoE's goal was to offer nurses educational programs on evidence-based cessation interventions and engagement in tobacco control. The CoE offered technical assistance to partners in each of the five target countries: Czech Republic (CZ), Hungary (HU), Romania (RO), Slovakia (SK), and Slovenia (SI). This is a first multi-country Centre of Excellence focused on nurses and tobacco control.

\section{Centre of Excellence development and planning}

An initial step was to create a network of partners that could support the goals of the CoE, creating a Tobacco Control Advisory Group (TCAG), with representation from regional nurse and physician tobacco control experts, followed by identifying nurse leaders based upon existing relationships ${ }^{13,14,16,27}$. A quarterly newsletter (https://www.isncc.org/page/ $\mathrm{COE}$ ), translated into all five languages facilitated information sharing among and within each country's 
team. Each country received funding to provide stipends and support project activities.

The project team communications were facilitated through email and the creation of a web-based platform on the ISNCC website where all documents in the language of the country were uploaded and made available. In the first two years of the CoE, a total of 379 documents in the five languages plus English were uploaded. Materials also were housed on the Tobacco-Free nurses' website.

\section{Educational programs}

Two methods were used to expand capacity: 1) inperson Training of Trainers (ToT) workshops, and 2) an online e-learning, including the development of country-specific web-based resources. Additionally, based upon the researchers experience in the US and because of the high rates of smoking among nurses in the region, focus groups were held with nurses who smoked and nurses who quit smoking to understand how to address this potential barrier for nurses' engagement in cessation interventions ${ }^{25,26}$. The focus groups confirmed that nurses had several misperceptions about tobacco addiction. Nurses also expressed concern about engaging with patients who smoke and whether this could be a cause of stress for patients or for their rapport with the patients. Addiction, smokers' willingness to receive advice, and best ways to start a conversation, were topics covered in the online education program.

The content of evidence-based educational programs was based upon an established evidencebased guideline for tobacco dependence treatment (i.e. the 5 As approach) ${ }^{12-14}$, and was reviewed by the Tobacco Control Advisory Group. Materials were translated, adapted and revised by experts from each of the five countries. Forward and backward translation of a sample, representing $20 \%$ of all materials in each of the languages, by nursing leaders assessed consistency of the content. A Manual of Procedures ensured fidelity in implementation of the CoE's activities. Nurse-focused evidence-based clinical cessation intervention guidelines were developed for each country. These were printed and distributed through national nursing events, in participating institutions, and made available online. Ethics/ Institutional Review Board (IRB) review and approval was obtained by the appropriate boards in each of the countries and the two US-based academic institutions, prior to the implementation of the online learning programs.

\section{Training of Trainers workshops and seminars}

Standardized one-day ToT workshops, based on the prior experience in the Czech Republic ${ }^{14,16}$, were implemented. The program covered a range of tobacco control areas, emphasising role-playing of cessation interventions and active engagement of participants ${ }^{14}$.

The ToT program was delivered by the country's nurse leader, although a nurse leader from Czech Republic participated in the first two workshops held in each country to ensure fidelity of the implementation. Nurse leaders recruited participants through notices in their home institutions, contacts with nursing organizations, calling nursing directors in different healthcare facilities, and, in several instances, the nurse leaders received calls requesting the workshops. Participants received an electronic copy of all materials and an additional slide set for a short (45-60 minutes) seminar on cessation intervention that could be implemented in their home institutions. The ToT was an important step in identifying nurses who could then champion and support the online education components.

From 2014-2016, 753 nurses participated in a total of 37 workshops (Czech Republic 314, Hungary 167, Romania 106, Slovakia 99, Slovenia 67 ), surpassing the initial goal of 20 nurses per workshop. Three to six months after the workshop, participants were followed up with a phone call or email to assess what tobacco control-related activities they had initiated. At least $60 \%$ of the nurses surveyed had implemented an educational activity in their home institution, reaching an estimated additional 1000 nurses (based on respondents' estimates), and also engaged in offering cessation intervention to patients, family and/or co-workers. As an additional outcome, one participating institution in the Czech Republic, changed its nursing assessment form to include routine assessment of tobacco use and documenting advice to quit, which prompted the need for additional education (i.e. short seminars) about using the $5 \mathrm{As}$ approach in that institution, thus reaching an additional 459 nurses. 


\section{Online learning.}

We developed brief web-based pre-recorded lectures and accompanying slides, adapted for each country's unique characteristics ${ }^{13,14,16,19-22}$.

\section{Design of the online program evaluation}

We used a prospective single group, pre-post design to assess the impact of the online educational program in increasing nurses' self-reported implementation of cessation interventions, and self-reported changes in their attitudes towards tobacco control in five countries in Central and Eastern Europe.

\section{Framework}

The RE-AIM Model (Reach, Effectiveness, Adoption, Implementation and Maintenance) was used as a framework to guide CoE's dissemination activities focused on nurses' delivery of tobacco dependence treatment, providing benchmarks for evaluation ${ }^{24}$.

Reach - was defined as the number of nurses in each country involved in the educational efforts.

Effectiveness - was defined as the implementation of the evidence-based tobacco dependence treatment educational programs by the nurses in the various healthcare facilities.

Adoption - indicated the number of nurses who adopted tobacco dependence interventions as selfreported in their participation in the follow-up evaluation.

Implementation - referred to the increase in the proportion of nurses who self-reported consistently (usually/always) delivering a tobacco dependence treatment intervention after program participation.

Maintenance - was defined as evidence from reports from nurse leaders in each country about integration of tobacco dependence treatment in healthcare systems and other institutional and policy changes.

\section{Participants}

The goal for the online program was to recruit a purposive sample of nurses (minimum target of 500, or 100 per country), aged $>18$ years, who worked at least $50 \%$ of time, providing direct care to adult patients in each of the five target countries. Nurses who worked in paediatrics, and nurses who did not provide direct patient care were excluded. Nurses who did not provide an e-mail address for follow-up were also excluded. Additionally, nurses who did not complete the questions about cessation interventions (5As) were also excluded after initial completion of the baseline survey. The sample size target was calculated to ensure that we could detect differences from baseline to follow-up at 3 months, with a $p<0.05$ level of significance.

\section{Online learning data collection}

\section{Recruitment and procedures}

The procedures are described in Figure 1. As there was no upper limit on the number of nurses that could participate, the final sample size was larger than anticipated. However, the desired 100 per country was not reached. Countries where nurses' access to online learning is just emerging, the level of engagement of nurse champions in each country and their preferences for online versus in-person learning, and national support for tobacco control, were all factors that may have influenced the discrepancy in sample size per country.

\section{Survey instrument}

The online baseline survey 'Helping Smokers Quit', a 28-item instrument assessed nurses' cessation intervention practices, including recommending smoke-free homes. It also included items on nurses' attitudes related to providing tobacco dependence treatment and two questions asked about their perception on the importance of nurses' involvement in tobacco control (not reported). One item asked the nurses to estimate the number of patients counselled to quit tobacco in the previous week. The post-test also assessed usability, acceptability and accessibility of the e-learning programs. The online survey used REDCap $^{\text {TM }}$ (Research Electronic Data Capture), a secure, web-based data capture tool for data collection and management ${ }^{28}$. The consents, surveys and each of the 112 REDCap $^{\mathrm{TM}}$ program keys (messages and warnings that pop-up during an online survey) were translated into each of the five languages. Data were collected in the period December 2015 to June 2016.

\section{Intervention}

Two webcasts were recorded using a prepared script in each country's native language to ensure consistency and fidelity of the content, with variations only to accommodate country-specific data. One 


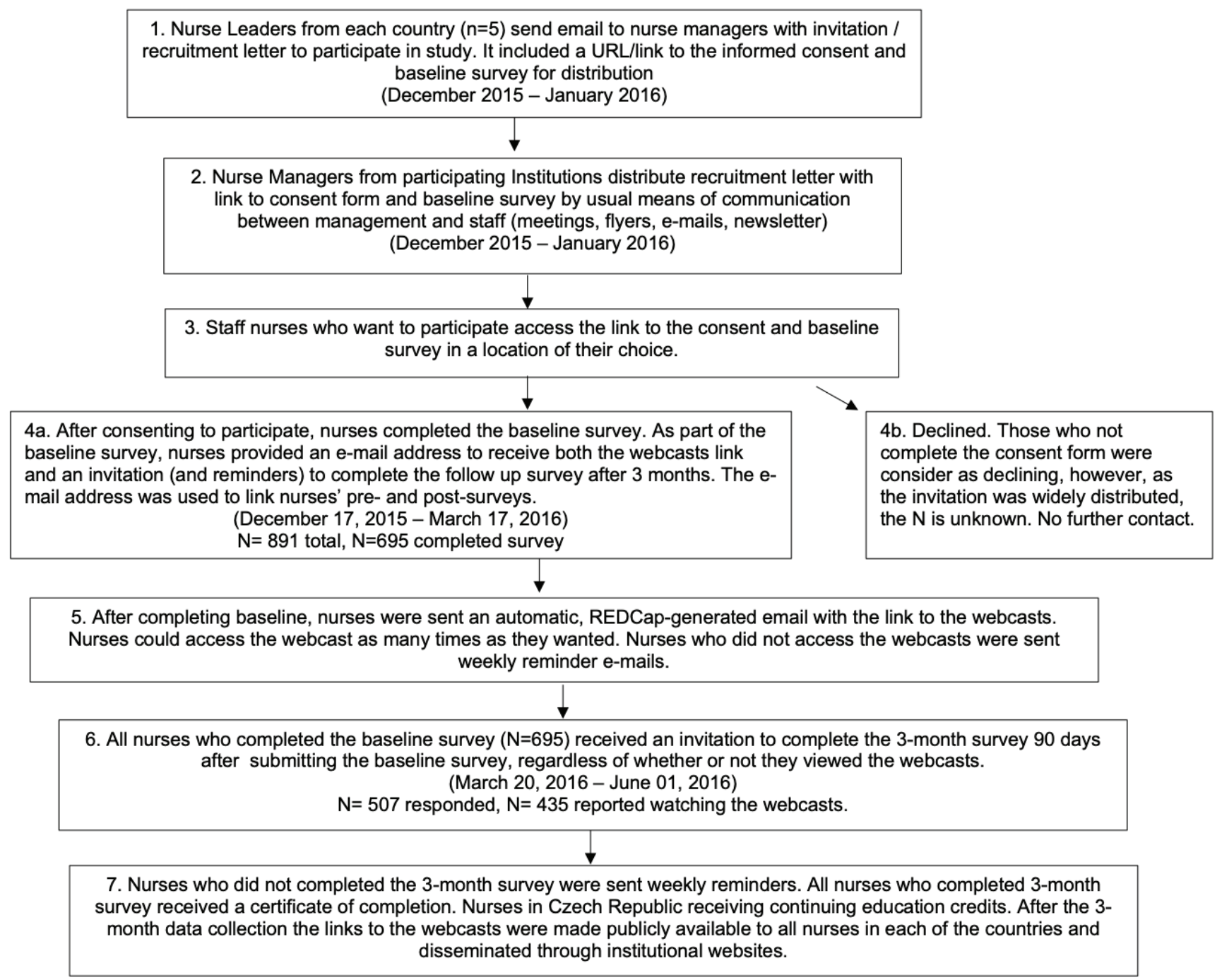

webcast focused on nurses and tobacco dependence treatment ( 45 minutes), the other on tobacco use cessation within oncology settings (30 minutes).

\section{Data analysis}

All data analyses used SAS 9.4. Demographic characteristics were presented as means with standard deviations or frequencies with per cent. For dichotomized outcomes, the significance level in change from baseline to follow-up was calculated using McNemar tests; while for all Likert-scale outcomes, the significance level for change from baseline to follow-up was calculated using Friedman tests. Generalized Linear Mixed Models were used for each dichotomized outcome to find predictors of consistently (defined as self-reported usually/ always) providing intervention. Each model included all possible predictors as well as an adjustment for country of origin.

\section{Validity, reliability and rigor}

The instrument was previously assessed for reliability ${ }^{13,14}$. Validity was established by expert review from the advisory board as well as nursing representatives in each of the countries.

\section{RESULTS}

Evaluation of the success of the CoE included an assessment of the number of nurses who participated in the education program and the nurses' self-reported 
increase in the delivery of tobacco dependence intervention as well as any changes in their perception of nurses' role in providing this intervention.

\section{Online education program}

Of the 891 nurses who answered the baseline survey, 695 nurses answered the questions on cessation interventions (i.e. 5As) and are included in the baseline analysis. The follow-up survey at 3 months

Table 1. Demographics, professional characteristics, and smoking status of nurses who completed both the baseline and the follow-up survey at 3 months $(\mathrm{N}=507)^{*}$

\begin{tabular}{|c|c|c|}
\hline Characteristics & $n$ & $\%$ \\
\hline \multicolumn{3}{|l|}{ Country } \\
\hline Czech Republic & 277 & 54.6 \\
\hline Hungary & 112 & 22.1 \\
\hline Romania & 37 & 7.3 \\
\hline Slovakia & 18 & 3.5 \\
\hline Slovenia & 63 & 12.4 \\
\hline Age (years), mean $\pm S D$ & \multicolumn{2}{|c|}{$43.34 \pm 10.17$} \\
\hline Years of practice, mean \pm SD & \multicolumn{2}{|c|}{$20.38 \pm 10.98$} \\
\hline \multicolumn{3}{|l|}{ Sex } \\
\hline Female & 473 & 95.9 \\
\hline Male & 20 & 4.1 \\
\hline \multicolumn{3}{|l|}{ Smoking status } \\
\hline Never & 300 & 60.7 \\
\hline Former & 116 & 23.5 \\
\hline Current & 78 & 15.8 \\
\hline \multicolumn{3}{|l|}{ Professional level } \\
\hline High school diploma or vocational in nursing & 342 & 69.4 \\
\hline Bachelor's degree & 98 & 19.9 \\
\hline Master's or doctorate degree & 53 & 10.7 \\
\hline \multicolumn{3}{|l|}{ Clinical practice } \\
\hline Internal medicine & 123 & 24.8 \\
\hline Ambulatory/primary/urgent care clinic & 88 & 17.7 \\
\hline Critical/intensive care & 54 & 10.9 \\
\hline Psychiatric/neurology/mental health & 53 & 10.7 \\
\hline Family medicine/visiting nurse & 51 & 10.3 \\
\hline Surgical & 51 & 10.3 \\
\hline Oncology & 27 & 5.4 \\
\hline Long-term care/rehabilitation unit & 31 & 6.2 \\
\hline Obstetrics/maternity/gynecology & 11 & 2.2 \\
\hline Hospice/palliative care & 5 & 1.0 \\
\hline Emergency room (ER/ED)/trauma unit & 2 & 0.4 \\
\hline
\end{tabular}

*Data were collected in the period December 2015 to June 2016. was completed by 507 (73\%) nurses (Figure 1). There were no significant differences at baseline between nurses who completed the follow-up and nurses who did not, thus it is unlikely that their absence created a systematic bias in the results.

Table 1 describes the country of origin, demographic and professional characteristics, and smoking status of the 507 participants with complete baseline and follow-up data; those with incomplete data were excluded from analysis. The majority (54.6\%) of nurses were from the Czech Republic, female, had a diploma degree (69\%), mean age of 43 years, and 20 years of practice. Sixty per cent were never smokers. The majority $(85.8 \%)$ of nurses reported watching the webcasts, and of those who watched, $98 \%$ found the webcast on cessation intervention useful or somewhat useful, and 95\% found the webcast on cessation for cancer patients useful or somewhat useful (data not shown).

Table 2 displays nurses' self-reported smoking cessation interventions with patients at baseline and at 3 months post-participation in the online program. There was a significant increase in all 5A components, as well as an increase in reviewing patient's perceived barriers to quitting and an increase in recommendations of advice for the creation of a smoke-free home environment post-

Table 2. Nurses self-reported frequency of providing smoking cessation interventions and recommending the creation of a smoke-free home, to patients at baseline and at 3 months post-participation in an online educational program $(\mathrm{N}=507)$

\begin{tabular}{lccc} 
Intervention & \multicolumn{3}{c}{ Response of nurses } \\
& At baseline & At 3 months & $p^{4}$ \\
& $n(\%)$ & $n(\%)$ & 0.01 \\
$\begin{array}{l}\text { Ask about a patient's } \\
\text { tobacco use }\end{array}$ & & & \\
$\begin{array}{l}\text { Sometimes/rarely/never } \\
\text { Usually/always }\end{array}$ & $150(29.6)$ & $124(24.6)$ & \\
$\begin{array}{l}\text { Advise a patient to quit } \\
\text { smoking }\end{array}$ & $357(70.4)$ & $380(75.4)$ & \\
$\begin{array}{l}\text { Sometimes/rarely/never } \\
\text { Usually/always }\end{array}$ & $174(34.3)$ & $125(24.6)$ & \\
$\begin{array}{l}\text { Assess patient's interest } \\
\text { in quitting }\end{array}$ & $333(65.7)$ & $382(75.4)$ & \\
$\begin{array}{l}\text { Sometimes/rarely/never } \\
\text { Usually/always }\end{array}$ & $210(41.4)$ & $172(33.9)$ & \\
& $297(58.6)$ & $335(66.1)$ &
\end{tabular}


Table 2. Continued

\begin{tabular}{|c|c|c|c|}
\hline \multirow[t]{2}{*}{ Intervention } & \multicolumn{3}{|c|}{ Response of nurses } \\
\hline & $\begin{array}{c}\text { At baseline } \\
n(\%)\end{array}$ & $\begin{array}{c}\text { At } 3 \text { months } \\
n(\%)\end{array}$ & $p^{a}$ \\
\hline $\begin{array}{l}\text { Assist a patient with } \\
\text { smoking cessation }\end{array}$ & & & $<0.0001$ \\
\hline Sometimes/rarely/never & $323(63.7)$ & $257(50.7)$ & \\
\hline Usually/always & $184(36.3)$ & $250(49.3)$ & \\
\hline $\begin{array}{l}\text { Arrange smoking } \\
\text { cessation follow-up }\end{array}$ & & & $<0.0001$ \\
\hline Sometimes/rarely/never & 403 (79.6) & 361 (71.3) & \\
\hline Usually/always & 103 (20.4) & $145(28.7)$ & \\
\hline $\begin{array}{l}\text { Recommend the use of } \\
\text { a telephone quitline for } \\
\text { smoking cessation }\end{array}$ & & & $<0.0001$ \\
\hline Sometimes/rarely/never & $379(74.8)$ & 287 (56.7) & \\
\hline Usually/always & $128(25.3)$ & $219(43.3)$ & \\
\hline $\begin{array}{l}\text { Recommend tobacco } \\
\text { cessation medications }\end{array}$ & & & $<0.0001$ \\
\hline Sometimes/rarely/never & $398(78.5)$ & $336(66.4)$ & \\
\hline Usually/always & $109(21.5)$ & $170(33.6)$ & \\
\hline $\begin{array}{l}\text { Review barriers to } \\
\text { quitting with patients } \\
\text { unwilling to make a quit } \\
\text { attempt }\end{array}$ & & & $<0.0001$ \\
\hline Sometimes/rarely/never & $321(63.44)$ & $234(46.3)$ & \\
\hline Usually/always & $185(36.56)$ & $272(53.7)$ & \\
\hline $\begin{array}{l}\text { Recommend creating } \\
\text { a smoke-free home } \\
\text { environment after } \\
\text { leaving the hospital }\end{array}$ & & & $<0.0001$ \\
\hline Sometimes/rarely/never & $268(52.86)$ & $197(38.9)$ & \\
\hline Usually/always & $239(47.14)$ & $310(61.1)$ & \\
\hline
\end{tabular}

discharge.

There was a significant change in nurses' agreement that they should be smoke-free role models from baseline to 3 months post-education $(p=0.03$, data not shown $)$. There was also a significant positive change in nurses agreeing that it is important for nurses to be involved in tobacco control, even when compared to other disease prevention activities (data not shown).

There was a significant increase in nurses believing that they can increase the likelihood of a patient quitting through asking about their smoking status (Table 3), and a significant increase in nurses believing cessation intervention was an efficient use of their time, that patients appreciate their cessation advice, and that offering cessation support improves their relationship with patients. Additionally, there was a significant increase in the number of nurses that stated they needed more cessation training, but nurses at both points in time disagreed that they did not have time to provide quitting support to their patients.

At 3 months, significantly $(\mathrm{p}<0.0001)$ more nurses reported that they provided cessation intervention to one or more patients in the previous week, compared to no patients receiving an intervention. The proportion of nurses that responded 'none' to the question estimating how many patients they provided cessation support in the previous week was $36.4 \%$ at baseline decreasing to $25.1 \%$ at 3 months. The proportion of nurses that estimated that they provided cessation intervention to $3-5$ patients in

a Chi-squared test

Table 3. Changes in nurses from five Central and Eastern European countries self-reported attitudes and opinions towards providing smoking cessation intervention to patients at baseline and at 3 months after participation in an online education program $(\mathrm{N}=507)$

Please rate the extent to which you agree with the

following statements
At baseline

At 3 months

$p$

\begin{tabular}{|c|c|c|c|c|c|}
\hline & $\begin{array}{c}\text { Strongly } \\
\text { disagree/ } \\
\text { Disagree/ } \\
\text { Neutral } \\
n(\%)\end{array}$ & $\begin{array}{c}\text { Agree/ } \\
\text { Strongly } \\
\text { agree } \\
n(\%)\end{array}$ & $\begin{array}{c}\text { Strongly } \\
\text { disagree/ } \\
\text { Disagree/ } \\
\text { Neutral } \\
n(\%)\end{array}$ & $\begin{array}{c}\text { Agree/ } \\
\text { Strongly } \\
\text { agree } \\
n(\%)\end{array}$ & \\
\hline $\begin{array}{l}\text { Asking patients about smoking increases the likelihood } \\
\text { that they will quit }\end{array}$ & $322(64.27)$ & $179(35.73)$ & $247(48.91)$ & $258(51.09)$ & $<0.0001$ \\
\hline It is difficult for me to get people to quit smoking & $227(45.67)$ & $270(54.33)$ & $229(45.44)$ & $275(54.56)$ & 0.87 \\
\hline
\end{tabular}

Continued 
Table 3. Continued

\begin{tabular}{|c|c|c|c|c|c|}
\hline \multirow{2}{*}{$\begin{array}{l}\text { Please rate the extent to which you agree with the } \\
\text { following statements }\end{array}$} & \multicolumn{2}{|c|}{ At baseline } & \multicolumn{2}{|c|}{ At 3 months } & \multirow[t]{2}{*}{$p$} \\
\hline & $\begin{array}{c}\text { Strongly } \\
\text { disagree/ } \\
\text { Disagree/ } \\
\text { Neutral } \\
n(\%)\end{array}$ & $\begin{array}{c}\text { Agree/ } \\
\text { Strongly } \\
\text { agree } \\
n(\%)\end{array}$ & $\begin{array}{c}\text { Strongly } \\
\text { disagree/ } \\
\text { Disagree/ } \\
\text { Neutral } \\
n(\%)\end{array}$ & $\begin{array}{c}\text { Agree/ } \\
\text { Strongly } \\
\text { agree } \\
n(\%)\end{array}$ & \\
\hline $\begin{array}{l}\text { Counseling patients about quitting is not an efficient use } \\
\text { of my time }\end{array}$ & $358(71.89)$ & $140(28.11)$ & $391(77.58)$ & $113(22.42)$ & 0.008 \\
\hline $\begin{array}{l}\text { Patients appreciate it when I provide advice about quitting } \\
\text { smoking }\end{array}$ & $226(45.20)$ & $274(54.80)$ & $186(39.83)$ & $281(60.17)$ & 0.01 \\
\hline $\begin{array}{l}\text { Discussing smoking cessation improves my relationship } \\
\text { with patients }\end{array}$ & $264(53.01)$ & 234 (46.99) & $236(46.92)$ & 267 (53.08) & 0.03 \\
\hline I feel uncomfortable asking patients whether they smoke & $429(86.84)$ & $65(13.16)$ & $422(83.73)$ & $82(16.27)$ & 0.12 \\
\hline $\begin{array}{l}\text { As a nurse, I can play an important role in helping patients } \\
\text { quit }\end{array}$ & $128(25.70)$ & $370(74.30)$ & $145(28.77)$ & $359(71.23)$ & 0.13 \\
\hline I need more training to help patients quit smoking & 156 (31.39) & $341(68.61)$ & $201(39.96)$ & $302(60.04)$ & 0.0005 \\
\hline $\begin{array}{l}\text { I have insufficient time to counsel patients about quitting } \\
\text { smoking }\end{array}$ & 389 (78.59) & $106(21.41)$ & $392(77.78)$ & $112(22.22)$ & 0.91 \\
\hline $\begin{array}{l}\text { I should take a more active role in helping patients to quit } \\
\text { smoking }(P)\end{array}$ & $224(45.25)$ & $271(54.75)$ & $245(48.61)$ & 259 (51.39) & 0.16 \\
\hline $\begin{array}{l}\text { Patients will be offended if I inquire about their smoking } \\
\text { status (N) }\end{array}$ & $351(70.91)$ & $144(29.09)$ & $353(69.90)$ & $152(30.10)$ & 0.63 \\
\hline $\begin{array}{l}\text { Providing tobacco cessation counseling is important to our } \\
\text { hospital even if only a few patients quit }(\mathrm{P})\end{array}$ & 115 (23.33) & 378 (76.67) & $103(20.56)$ & $398(79.44)$ & 0.23 \\
\hline I have an obligation to advise patients on the health risks & $131(26.73)$ & $359(73.27)$ & $107(21.57)$ & $389(78.43)$ & 0.01 \\
\hline
\end{tabular}
associated with tobacco use (P)

P: positive. N: negative.

Table 4. Predictors of consistently (usually/always) providing tobacco dependence treatment interventions 3 months after exposure to an online educational program change among nurses in five Central and Eastern European countries $(\mathrm{N}=507)$

Variable Ask Advise Assess $\quad \begin{gathered}\text { Assist } \\ \text { Arrange }\end{gathered} \begin{gathered}\begin{array}{c}\text { Refer to } \\ \text { quitline }\end{array} \\ \text { smoke-free } \\ \text { home }\end{gathered}$
OR $(95 \% \mathrm{CI})$

Time

3 months vs baseline $\quad 1.30(0.96-1.77) \quad 1.67^{* *}(1.23-2.72) \quad 1.41^{*}(1.07-1.87) \quad 1.94^{* *}(1.45-2.59) \quad 1.76^{* *}(1.25-2.48) \quad 2.50^{* *}(1.85-3.40) \quad 1.90^{* *}(1.43-2.51)$ Age $\quad 1.01(0.99-1.02) \quad 1.05^{* *}(1.03-1.07) \quad 1.02^{* *}(1.01-1.04) \quad 1.03^{* *}(1.01-1.05) \quad 1.05^{* *}(1.03-1.07) \quad 1.04^{* *}(1.02-1.06) \quad 1.04^{* *}(1.02-1.06)$

Smoking status

Current smoker vs never $\quad 1.39(0.87-2.21) \quad 1.17(0.74-1.85) \quad 1.20(0.80-1.82) \quad 1.60^{*}(1.03-2.50) \quad 1.62^{*}(1.01-2.61) \quad 1.83^{* *}(1.18-2.84) \quad 1.20(0.79-1.82)$ smoker

Former smoker vs never $\quad 1.03(0.61-1.75) \quad 0.58^{*}(0.35-0.97) \quad 0.72(0.45-1.16) \quad 0.79(0.46-1.33) \quad 0.34^{* *}(0.17-0.71) \quad 0.73(0.42-1.26) \quad 0.70(0.43-1.13)$ smoker

Education

Non-baccalaureate vs $\quad 0.81(0.53-1.23) \quad 0.75(0.50-1.14) \quad 0.75(0.52-1.09) \quad 0.75(0.50-1.13) \quad 0.49^{* *}(0.31-0.76) \quad 1.10(0.73-1.66) \quad 0.57^{* *}(0.39-0.84)$ baccalaureate or more

${ }^{*} \mathrm{p}<0.05, \mathrm{p}^{* *}<0.01$. Generalized Linear Mixed Model for a binary outcome, adjusted for country. 
the previous week increased from $12 \%$ to $19 \%$ (data not shown).

Table 4 displays the predictors of nurses consistently (usually/always) providing cessation interventions to patients at 3 months postparticipation in the online program. Nurses who were current smokers were $60 \%$ more likely to Assist and Arrange, and 83\% more likely to Refer to a quitline compared to never smokers. Nurses who were former smokers were less likely than nurses who never smoked to Arrange for a follow-up.

\section{DISCUSSION}

The CoE for nurses and tobacco control in Central and Eastern Europe was a pioneering initiative that has enhanced nurses' access to education about evidencebased tobacco dependence treatment and tobacco control. By April 2019, all countries, including the Republic of Moldova, continued with their workshop activities, online learning and public events and are currently seeking additional funding. At country level, engaging with nursing leadership to support the online learning was pivotal to creating support for nurses' role in tobacco dependence treatment. The creation of a support network of nurses that can champion nurses' role in tobacco dependence treatment at the country level, while not the main objective of this paper, proved to be important in creating a multi-country support system that still exists.

The online educational program and web-based resources had a significant impact on nurses selfreported intervention with patients, confirming what others have found in clinical trials ${ }^{29}$. Additionally, it created a network of nurse champions who are poised to become leaders in tobacco control in their countries. Nurse champions have helped raise the profile of the importance nurses' engagement in tobacco control through their efforts to promote the CoE within their own national societies and schools of nursing. The positive changes in nurses' attitudes towards their role in tobacco control and how cessation can help instead of hindering their relationship with patients, was encouraging. It demonstrates that with proper information nurses are supportive of providing cessation interventions to their patients.

However, access to the online program was not uniform among the five countries. Nurses in Romania and Slovakia found it more difficult to participate, despite the efforts of the national nurse champions to encourage participation. Therefore, it is likely that in-person workshops, short seminars and online forms of education combined are necessary to ensure high levels of nursing engagement in cessation interventions.

The finding that nurses who were current smokers were significantly more likely to Assist and Arrange confirms that nurses are able to support patients quitting efforts, despite their own smoking status, although others have found that nurses who smoke were less likely to engage with patients. It indicates that the emphasis should be on educating nurses to provide excellent nursing care, including cessation support, as part of routine practice.

The RE-AIM was adequate to evaluate the development and impact of the educational program established through the CoE, but the duration of the initial years of the project might not have been sufficient to determine long-term maintenance of the program impact on nurses' behaviour.

\section{Limitations}

The CoE's development was not without challenges. Obtaining ethics board approval to allow collection of data in all institutions took time, and in some cases, it was the first-time approval given to a project lead by nurses. Therefore, even before the educational activities started the CoE promoted institutional changes in relation to the role of nurses in tobacco control and research. The lack of a control group limits the interpretation of the results as nurses may have self-selected to participate. The choice of not having a control group was based on the difficulty expressed by partners in withholding the educational program, even for the short time that it would take to collect follow-up data at 3 months. The nurses' country of origin was not equally represented in the sample. This could be a reflection on the normalization of smoking cessation in the country, the scope of practice as well as nurses' level of comfort in accessing an online learning platform. Czech Republic partners worked with their national nursing organization to provide continuing education credits to nurses who completed the program. This was the first accreditation provided to an online education program in the countries. 
Other countries' partners participation was driven by the country partners and the other countries.

We did not track how widely disseminated was each of the materials produced. Nurses had access to the webcasts for the 3 months and may have accessed them more than once. In some of the countries, the nurse managers organized a group viewing of the webcasts as part of nursing education and we have no information on how many nurses watched the webcast in this manner. In addition to uploading materials such as newsletters on the websites, some were mailed to participating institutions and organizations. At the end of the data collection, the online learning was available to be placed on the websites of participating institutions as well. Therefore, it is possible that there was a reach that was not captured by the evaluation we conducted.

While the infrastructure for growth and sustainability of activities to enhance nursing engagement in tobacco control has been developed, it is premature to estimate the direct impact on health and nursing practice for each nation. Several of the nurse champions started to outreach to nursing schools and nursing faculty, offering the educational programs to nursing students.

The team made all possible efforts to ensure that the educational activities across countries followed a pre-established, agreed upon protocol, but as with all human interactions, slight variations likely occurred.

\section{Future directions}

As the CoE continues to grow and expand, changes in nursing practice in tobacco control continue to be monitored. Additionally, system changes in healthcare institutions that facilitate nurses' engagement in cessation interventions should also be monitored, such as the inclusion of tobacco assessment as part of the medical record in one Czech hospital, as the goal is to promote policy changes that provide access to evidence-based treatment to all patients who smoke. In Hungary, the program is expanding to reach all home health visitors and primary care clinics. In Romania, nurse leaders are engaging with schools of nursing and nursing students to promote education on tobacco dependence treatment. The establishment and maintenance of a variety of partnerships that could build a network in support of nurses' engagement in tobacco control activities was, and remains, pivotal to the long-term success of the $\mathrm{CoE}$ as is the integration of nurses' contribution into broader tobacco control efforts supporting the implementation of the FCTC.

\section{CONCLUSIONS}

We demonstrated the ability to cross geographical, sociocultural, economic and political differences to engage nurses in multiple countries in a common goal - the reduction of unnecessary death and suffering from tobacco use and exposure, through a Centre of Excellence coordinating the educational activities. The CoE was able to mentor and support nurse champions who are becoming tobacco control leaders in their countries.

The COE offers a model to build capacity, expand nurses' role, and engage nurses to implement evidence-based interventions that will contribute to reaching global health and development targets. The International Council of Nurses has acknowledged the pivotal role that nurses will play in reaching the $\mathrm{SDGs}^{30}$, and nurses are in an ideal position for involvement in non-communicable diseases $(\mathrm{NCDs})^{31}$. The CoE provides a model structure and mechanisms for dissemination that the 'Nursing Now' campaign ${ }^{32}$ can use. The CoE promotes nurses' engagement in policy, addressing SDG through grass-roots mobilization, changes in nursing standards of practice and contributes to policy changes that facilitate smoking cessation.

\section{REFERENCES}

1. World Health Organization. Nursing and midwifery. https://www.euro.who.int/en/health-topics/Healthsystems/nursing-and-midwifery/nursing-and-midwifery. Accessed August 16, 2017.

2. World Health Organization. Towards A Global Action Plan For Healthy Lives And Well-Being For All: Uniting to accelerate progress towards the health-related SDGs. https://www.icn.ch/sites/default/files/inline-files/ Global_Action_Plan_Phase_I.PDF. Published 2018. Accessed October 5, 2018.

3. International Council of Nurses. ICN Strategic Priorities: Sustainable Development Goals. https://www.icn.ch/ nursing-policy/icn-strategic-priorities/sustainabledevelopment-goals. Accessed October 5, 2018.

4. World Health Organization. Tobacco Fact Sheet. http:// www.who.int/mediacentre/factsheets/fs339/en/. Updated May 27, 2020. Accessed June 21, 2017.

5. World Health Organization. Tobacco Free Initiative: WHO report on the global tobacco epidemic 2015. http://www. who.int/tobacco/global_report/2015/en/. Published 
2015. Accessed June 21, 2017.

6. World Health Organization. Data and statistics. http:// www.euro.who.int/en/health-topics/disease-prevention/ tobacco/data-and-statistics. Accessed August 21, 2017.

7. Islami F, Torre LA, Jemal A. Global trends of lung cancer mortality and smoking prevalence. Transl Lung Cancer Res. 2015;4(4):327-338. doi:10.3978/j.issn.22186751.2015.08.04

8. World Health Organization. The Cancer Atlas, 2017. https://canceratlas.cancer.org/the-burden/europe/. Accessed June 21, 2017.

9. World Health Organization. State of the world's nursing 2020: investing in education, jobs and leadership. https:// apps.who.int/iris/handle/10665/331677. Published 2020. Accessed August 31, 2020.

10. World Health Organization. About the WHO Framework Convention on Tobacco Control. http://www.who.int/ fctc/about/en/. Published 2017. Accessed June 21, 2017.

11. World Health Organization. Guidelines for implementation of Article 14: Guidelines on demand reduction measures concerning tobacco dependence and cessation. In: Conference of the Parties at its fourth session (decision FCTC/COP4(8)). https://www.who.int/fctc/treaty_ instruments/adopted/Guidelines_Article_14_English. pdf?ua=1. Accessed August 16, 2017.

12. U.S. Department of Health and Human Services. A clinical practice guideline for treating tobacco use and dependence: 2008 update. A U.S. Public Health Service report. Am J Prev Med. 2008;35(2):158-176. doi:10.1016/j.amepre.2008.04.009

13. Bialous SA, Sarna L, Wells MJ, et al. Impact of online education on nurses' delivery of smoking cessation interventions with implications for evidence-based practice. Worldviews Evid Based Nurs. 2017;14(5):367376. doi:10.1111/wvn.12197

14. Sarna L, Bialous SA, Kralikova E, et al. Impact of a smoking cessation educational program on nurses' interventions. J Nurs Scholarsh. 2014;46(5):314-321. doi:10.1111/jnu.12086

15. Warren CW, Sinha DN, Lee J, Lea V, Jones NR. Tobacco use, exposure to secondhand smoke, and training on cessation counseling among nursing students: crosscountry data from the Global Health Professions Student Survey (GHPSS), 2005-2009. Int J Environ Res Public Health. 2009;6(10):2534-2549. doi:10.3390/ ijerph6102534

16. Sarna L, Bialous SA, Kralikova E, et al. Tobacco Cessation Practices and Attitudes Among Nurses in the Czech Republic. Cancer Nurs. 2015;38(6):E22-E29. doi:10.1097/NCC.0000000000000222

17. Bialous SA, Sarna L. Lung Cancer and Tobacco: What Is New?. Nurs Clin North Am. 2017;52(1):53-63. doi:10.1016/j.cnur.2016.10.003

18. Sarna L, Bialous SA, Ong M, Wells M, Kotlerman J. Nurses' treatment of tobacco dependence in hospitalized smokers in three states. Res Nurs Health. 2012;35(3):250-264. doi:10.1002/nur.21476

19. Sarna L, Bialous SA, Ong M, Wells M, Kotlerman J. Increasing nursing referral to telephone quitlines for smoking cessation using a web-based program. Nurs Res. 2012;61(6):433-440. doi:10.1097/ NNR.0b013e3182707237

20. Sarna L, Bialous SA, Wells M, Brook J. Impact of a webcast on nurses' delivery of tobacco dependence treatment. J Clin Nurs. 2018;27(1-2):e91-e99. doi:10.1111/ jocn. 13875

21. Sarna L, Bialous SA, Xiao Z, et al. Helping smokers quit: behaviours and attitudes of Chinese Registered Nurses. J Adv Nurs. 2016;72(1):107-117. doi:10.1111/jan.12811

22. SarnaL, Bialous SA, Xiao Z, et al. Evaluation of a webbased educational programme on changes in frequency of nurses' interventions to help smokers quit and reduce second-hand smoke exposure in China. J Adv Nurs. 2016;72(1):118-126. doi:10.1111/jan.12816

23. Bristol-Myers Squibb. Bristol-Myers Squibb Foundation Announces Two Grants to Fund Cancer Nursing Centers of Excellence in Russia and the Czech Republic. https:// news.bms.com/news/details/2013/Bristol-MyersSquibb-Foundation-Announces-Two-Grants-to-FundCancer-Nursing-Centers-of-Excellence-in-Russia-andthe-Czech-Republic/default.aspx. Published October 12, 2013. Accessed May 5, 2018.

24. Bristol-Myers Squibb. Bristol-Myers Squibb Foundation Announces Two Grants to Fund Cancer Nursing Centers of Excellence in Russia and the Czech Republic. https:// news.bms.com/news/details/2013/Bristol-MyersSquibb-Foundation-Announces-Two-Grants-to-FundCancer-Nursing-Centers-of-Excellence-in-Russia-andthe-Czech-Republic/default.aspx. Published October 12, 2013. Accessed May 5, 2018.

25. Petersen AB, Sarna L, Rezk-Hanna M, Wells M, Nohavova I, Bialous SA. 'Everyone Needs a Breath of Fresh Air': Workplace Impact on Nurses' Smoking Behaviors. Cancer Nurs. 2019;43(4):319-330. doi:10.1097/ NCG.0000000000000696

26. Rezk-Hanna M, Sarna L, Petersen A, Wells M, Nohavova I, Biaous SA. Attitudes, barriers and facilitators to smoking cessation among Central and Eastern European nurses: A focus group study. Eur J Oncol Nurs. 2018;35:39-46. doi:10.1016/j.ejon.2018.04.001

27. Kralikova E, Felbrova V, Kulovana S, et al. Nurses' Attitudes toward Intervening with Smokers: Their Knowledge, Opinion and E-Learning Impact. Cent Eur J Public Health. 2016;24(4):272-275. doi:10.21101/cejph. a4652

28. HarrisPA, Taylor R, Thielke R, Payne J, Gonzalez N, Conde J. Research electronic data capture (REDCap)-a metadata-driven methodology and workflow process for providing translational research informatics support. J Biomed Inform. 2009;42(2):377-381. doi:10.1016/j. 
jbi.2008.08.010

29. Semwal M, Whiting P, Bajpai S, Kyaw B, Tudor C. Digital Education for Health Professions on Smoking Cessation Management: Systematic Review by the Digital Health Education Collaboration. J Med Internet Res. 2019;21(3):e13000. doi:10.2196/13000

30. International Council of Nurses. Nurses' role in achieving the sustainable development goals. In: Nurses, A Voice to Lead: Achieving the SDGs. Geneva, Switzerland; 2017. https://www.icnvoicetolead.com/wp-content/ uploads/2017/04/ICN_AVoiceToLead_guidancePack-9. pdf. Accessed December 15, 2017.

31. World Health Organization. Health Workforce: Enhancing nursing and midwifery capacity to contribute to the prevention, treatment and management of noncommunicable diseases. In: Human Resources for Health Observer - Issue No. 12. https://www.who.int/ hrh/resources/observer12.pdf?ua=1. Published February, 2013. Accessed August 17, 2017.

32. Burdett Trust for Nursing. Nursing Now: Vision. https:// www.nursingnow.org/vision/. Published 2016. Accessed September 5, 2017.

\section{ACKNOWLEDGEMENTS}

We acknowledge all our partner institutions and nurse colleagues in participating countries including the Czech Republic: Centre for TobaccoDependent, 3rd Department of Medicine, 1st Faculty of Medicine, Charles University in Prague and General University Hospital in Prague, the Society for Treatment of Tobacco Dependence, the Military University Hospital Prague, and the Clinic of Radiotherapy and Oncology, Faculty Hospital Kralovske Vinohrady, Prague; Hungary: the National Korányi Institute for Pulmonology, Budapest; Republic of Moldova: Nursing Association of Moldova; Romania: the Romanian Nursing Association, Bucharest; Slovakia: the National Institute of Cardiovascular Diseases, Bratislava, Slovak Chamber of Nurses and Midwives; Slovenia: the Institute of Oncology Ljubljana, and the Angela Boškin Faculty of Health Care, Jesenice; and the United States: the University of California Los Angeles School of Nursing, and the University of California San Francisco School of Nursing. We would like to acknowledge the Society for Treatment of Tobacco Dependent in Prague for agreeing to house the Eastern Europe Nurses' Centre of Excellence for Tobacco Control.

\section{CONFLICTS OF INTEREST}

The authors have each completed and submitted an ICMJE form for disclosure of potential conflicts of interest. The authors declare that they have no competing interests, financial or otherwise, related to the current work. S. Bialous reports grants from Bristol-Myers Squibb Foundation during the conduct of the study, and grants from Pfizer Independent Medical Grants outside the submitted work.

\section{FUNDING}

This work was supported by a grant from the Bristol-Myers Squibb Foundation Bridging Cancer Care Initiative to the International Society of Nurses in Cancer Care, and with support from the UCLA School of Nursing's Lulu Wolf Hassenplug Endowed Chair. Use of REDCap ${ }^{\mathrm{TM}}$ (Research Electronic Data Capture) was provided by the UCLA Clinical \& Translational Science Institute (CTSI) Grant \#UL1TR001881. The funding organization had no involvement in the study design, the collection, analysis and interpretation of the data, the writing of the manuscript or in the decision to submit it for publication.

\section{AUTHORS' CONTRIBUTIONS}

LS, SB, IN, JB, MW and EK: Made substantial contributions to conception and design, or acquisition of data, or analysis and interpretation of data. LS and SB were involved in drafting the manuscript or revising it critically for important intellectual content. LS, SB, IN, MW, EK gave final approval of the version to be published. Each author has participated sufficiently in the work to take public responsibility for appropriate portions of the content. All authors have agreed on the final version and meet at least one of the following criteria [recommended by the ICMJE (http://www.icmje. org/recommendations/)]: Substantial contributions to the conception or design of the work; or the acquisition, analysis, or interpretation of data for the work; and drafting the work or revising it critically for important intellectual content.

PROVENANCE AND PEER REVIEW

Not commissioned; externally peer reviewed. 